\title{
Characterization and source identification of ambient volatile organic compounds (VOCs) in a heavy pollution episode in Beijing, China
}

\author{
Y. Q. Li, J. Li, R. R. Wu \& S. D. Xie \\ College of Environmental Sciences and Engineering, \\ Peking University, China
}

\begin{abstract}
102 ambient VOC species were measured online by a gas chromatography-mass spectrometry/flame ionization detector (GC/MS-FID) at an urban site in Beijing during a heavy pollution episode in December 2014. VOC sources were identified by correlation analysis of particular species pairs. The interspecies correlations of benzene-acetylene, toluene-acetylene, isobutane-propane and ethane-propane were analyzed by calculating the correlation coefficients. Major sources were concluded by comparing the linear regression slopes with previous studies. Alkanes provided the largest contribution to ambient VOCs, accounting for $38.9 \%$ of total VOCs; followed by alkenes and alkynes, accounting for $28.7 \%$ and $11.8 \%$, respectively. The most abundant VOC species include ethene, ethane, acetylene and propane, with hourly average mixing ratios of 14.85, 14.47, 9.69 and $7.27 \mathrm{ppbv}$, respectively. VOC groups including alkanes, alkenes and alkynes, and the most abundant species followed a similar pattern of average diurnal variation. VOC mixing ratios decreased after sunrise and reached a minimum value at noon (12:00-14:00), then increased in the afternoon and reached a peak value at night (22:00-23:00). This likely resulted from a descending boundary layer at night and possible night emissions. There was no pronounced diurnal variation in oxygenated VOCs (OVOCs). LPG-related sources and combustion sources were major VOC sources in this heavy pollution episode.

Keywords: ambient VOCs, heavy pollution, concentration levels, time series, diurnal variations, interspecies correlations, VOC sources.
\end{abstract}




\section{Introduction}

In recent years, volatile organic compounds (VOCs) have aroused considerable concern due to their adverse effect on human health [1] and their important role in formation of tropospheric ozone $\left(\mathrm{O}_{3}\right)$ and secondary organic aerosols (SOA) via photochemical process [2]. Studies have evidenced that some VOC species have carcinogenic nature. Benzene is a strong carcinogen; toluene is a toxicant for central nervous system [3,4]. In addition to the toxicity of VOC species themselves, SOA formed by atmospheric oxidation of VOCs can trigger severe air pollution, degradation in visibility and increase in respiratory symptoms [5].

The development of China has resulted in an inevitable increase in air pollution, especially haze pollution characterized by high levels of $\mathrm{PM}_{2.5}$ [6]. In 2013, severe haze events were observed in large cities including Beijing and Shanghai $[7,8]$, with hourly concentration level of $\mathrm{PM}_{2.5}$ up to $\sim 900 \mu \mathrm{g} / \mathrm{m}^{3}$. There were two severe haze events observed in North China Plain in December 2014, with daily average concentration of $\mathrm{PM}_{2.5}$ in Beijing approaching $220 \mu \mathrm{g} / \mathrm{m}^{3}$ [9]. Since VOCs are important precursors of tropospheric $\mathrm{O}_{3}$ and play a significant role in the formation of SOA, measurement and quantification of VOCs in the ambient air, as well as identification of VOC sources, are important for air quality assessment and for understanding the photochemical formation of haze pollution. There are studies focusing on the characterization and source identification of ambient VOCs in urban [4, 10] and rural areas [11, 12] around the world. Fanizza et al. [4] investigated the ambient VOC characteristics in summer and winter during 2011, at an urban site in Rome. The seasonal average concentrations of VOCs varied from $78 \mathrm{ppbv}$ in winter to $37 \mathrm{ppbv}$ in summer. The VOC levels in summer were close to an intensive measurement campaign conducted during May, 2009, at three urban sites in Shanghai, China [10]. A study targeted at the atmospheric levels and emission sources of BTEX (benzene, toluene, ethylbenzene, xylene) at an urban site in Beijing, during the 2008 Olympic Games [1]. The significantly positive correlation between BTEX and $\mathrm{CO}$ as well as the benzene/toluene ratio revealed that the major source of ambient VOCs was vehicular exhaust. Previous studies have provided essential information on characteristics and sources of VOCs in the ambient air in various regions. However, few studies have focused on the characterization of VOCs during heavy pollution episodes until now.

We focused on ambient VOC levels and sources in a heavy pollution episode in December 2014, in Beijing. Concentration data of 102 species of ambient VOCs were obtained on an hourly basis from an online system. The data were then quantified to identify the levels of different groups of VOCs and the most abundant VOCs species in the ambient air. The results were compared with previous studies in China and abroad. Diurnal variation patterns of VOC species were also investigated. VOC source identification was carried out by analyzing the correlations of species with low or similar chemical reactivity. The obtained results have enabled us to quantitatively learn about the chemical composition and concentration levels of ambient VOCs in the heavy pollution episode and to distinguish the major sources of VOCs. 


\section{Methodology}

\subsection{VOC sampling and analysis}

Measurement of ambient VOCs was carried out at an urban site in Beijing, which was located at the top floor of a 5-storey building of Department of Technical Physics, Peking University $\left(39.99^{\circ} \mathrm{N}, 116.33^{\circ} \mathrm{E}\right)$. The sampling site was around $20 \mathrm{~m}$ above ground. Since Peking University is located in a residential and commercial area in the northwest of Beijing and directly south of the sampling site is the 4th ring road that carries heavy traffic, ambient VOCs were mainly emitted from sources including vehicular emissions and fuel combustion [13].

Measurement was conducted during December 25 to December 30. Ambient VOC samples were collected and analyzed continuously and automatically by an online system, gas chromatography-mass spectrometry/flame ionization detector (GC/MS-FID) [14]. As listed in Table 1, 102 VOC species were identified and quantified. An external standard method was used for $\mathrm{C} 2-\mathrm{C} 5$ hydrocarbons quantification; an internal standard method was applied for MS quantification of VOCs. Four compounds were used as internal standards: bromochloromethane, 1,4-difluorobenzene, chlorobenzene-d5, and bromofluorobenzene. The $\mathrm{R}^{2}$ values of the calibration curves were above 0.99 for all VOC species $[13,15]$. The Method Detection Limit (MDL) of the online GC-MS/FID system for each species ranged from $0.002-0.070 \mathrm{ppbv}$ [14]. Detailed information on the online system is illustrated in Li et al. [13].

\subsection{Identification of VOC sources}

Since absolute mixing ratios of VOCs vary largely with time and space, correlation between individual VOC species, which have low or similar reactivity, can be used to provide important regional air quality information and to identify major sources of ambient VOCs $[15,16]$. We judged the interspecies correlations by Pearson correlation coefficients and estimated the ratios for specific species pairs by linear regression. The species indicators can provide information on sources and were commonly used in source identification in previous studies [15, 17-19]. By making comparisons between the linear regression slopes of this study and previous studies, major emission sources of ambient VOCs during this heavy pollution episode can be distinguished.

\section{Results and discussion}

\subsection{VOC mixing ratios}

\subsubsection{General characteristics of ambient VOCs}

Figure 1 presents the time series of total VOC mixing ratios during the heavy pollution episode. Total VOC mixing ratios increased with fluctuation during December 25 to 1:00, December 28, from a minimum value of 16.83 ppbv to a peak value of $253.20 \mathrm{ppbv}$. VOC mixing ratios then decreased expeditiously to 
Table 1: $\quad$ VOC species measured in this study.

\begin{tabular}{|c|c|c|}
\hline Alkanes (29) & 1-Pentene & Tetrachloromethane \\
\hline Ethane & trans-2-Pentene & 1,2-Dichloroethane \\
\hline Propane & Isoprene & Trichloroethylene \\
\hline Isobutane & cis-2-Pentene & 1,2-Dichloropropane \\
\hline n-Butane & 1-Hexene & Bromodichloromethane \\
\hline Cyclopentane & trans-1,3-Dichloropropene & cis-1,3-Dichloropropene \\
\hline Isopentane & & 1,1,2-Trichloroethane \\
\hline n-Pentane & Acetylene & Tetrachloroethylene \\
\hline 2,2-Dimethylbutane & & 1,2-Dibromoethane \\
\hline 2,3-Dimethylbutane & Aromatics (16) & Chlorobenzene \\
\hline 2-Methylpentane & Benzene & Bromoform \\
\hline Cyclopentane & Toluene & 1,1,2,2-Tetrachloroethane \\
\hline 3-Methylpentane & Ethylbenzene & 1,3-Dichlorobenzene \\
\hline n-Hexane & $\mathrm{m} / \mathrm{p}$-Xylene & 1,4-Dichlorobenzene \\
\hline 2,4-Dimethylpentane & o-Xylene & Benzylchloride \\
\hline Methylcyclopentane & Styrene & 1,2-Dichlorobenzene \\
\hline 2-Methylhexane & Isopropylbenzene & \\
\hline 2,3-Dimethylpentane & n-Propylbenzene & OVOCs (17) \\
\hline 3-Methylhexane & 3-Ethyltoluene & Acrolein \\
\hline 2,2,4-Trimethylpentane & 4-Ethyltoluene & Propanal \\
\hline n-Heptane & 1,3,5-Trimethylbenzene & Acetone \\
\hline Methylcyclohexane & 2-Ethyltoluene & Methylacetate \\
\hline 2,3,4-Trimethylpentane & 1,2,4-Trimethylbenzene & MTBE \\
\hline 2-Methylheptane & 1,2,3-Trimethylbenzene & Methacrolein \\
\hline 3-Methylheptane & 1,3-Diethylbenzene & Vinylacetate \\
\hline Octane & 1,4-Diethylbenzene & n-Butanal \\
\hline n-Nonane & & Methylvinylketone \\
\hline n-Decane & Halocarbons (26) & Methylethylketone \\
\hline Udecane & Chloromethane & Ethylacetate \\
\hline \multirow[t]{2}{*}{ Dodecane } & Vinylchloride & 2-Pentanone \\
\hline & Bromomethane & n-Pentanal \\
\hline Alkenes (12) & Chloroethane & 3-Pentanone \\
\hline Ethene & 1,1-Dichloroethylene & Methylmethacrylate \\
\hline Propene & Dichloromethane & n-Hexanal \\
\hline trans-2-Butene & 1,1-Dichloroethane & n-Butylacetate \\
\hline 1-Butene & cis-1,2-Dichloroethylene & \\
\hline cis-2-Butene & Chloroform & \\
\hline 1,3-Butadiene & 1,1,1-Trichloroethane & Acetonitrile \\
\hline
\end{tabular}

$23.00 \mathrm{ppbv}$ in 12 hours, due to passage of a low-pressure system that broke up the capping temperature inversion and brought in clean air from the Inner Mongolia. From 16:00, December 28, VOC mixing ratios rose up again and two peak values can be seen in December 29, with VOC mixing ratios of 186.16 and 164.73 ppbv, 
respectively. In December 30, VOC levels began to gradually decrease. In this heavy pollution episode, both highly elevated and rapidly reduced VOC levels were identified.

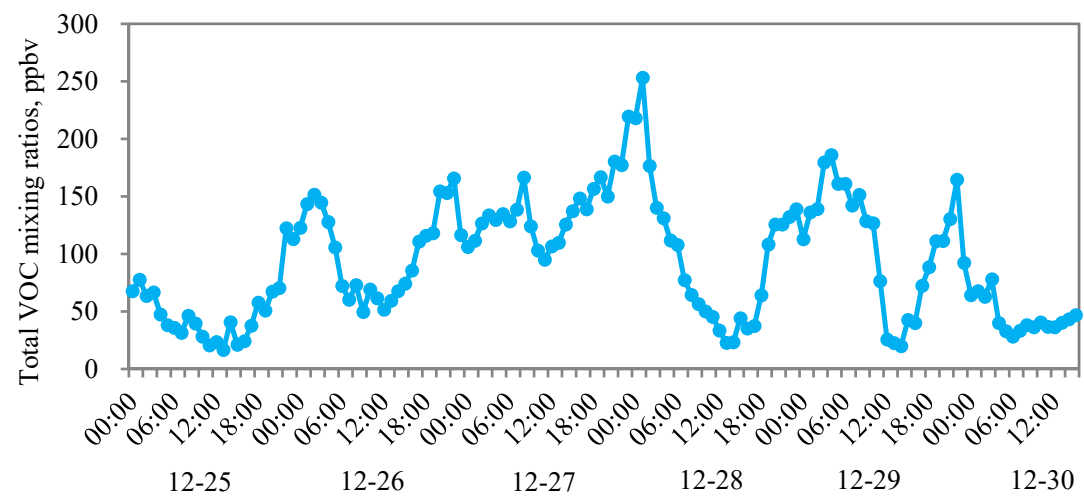

Figure 1: Time series of total VOC mixing ratios.

Among all VOC groups, alkanes, with an average mixing ratio of $32.08 \mathrm{ppbv}$, were the largest contributor to ambient VOCs, accounting for $38.9 \%$ of total VOCs. Alkenes ranked the second, with an average mixing ratio of $23.65 \mathrm{ppbv}$, accounting for $28.7 \%$ of total VOCs, followed by acetylene ( $9.69 \mathrm{ppbv}, 11.8 \%$ ), OVOCs (7.41 ppbv, 9.0\%), aromatics (5.22 ppbv, 6.3\%), and halocarbons (4.15 ppbv, 5.0\%). Top 20 VOC species with the highest average mixing ratio are summarized in Table 2. C2 C 4 alkanes, $\mathrm{C} 2 \sim \mathrm{C} 4$ alkenes and acetylene provided

Table 2: Top 20 most abundant species (ppbv) measured in this study.

\begin{tabular}{|l|l|l|l|l|c|}
\hline \multicolumn{1}{|c|}{ Species } & \multicolumn{1}{c|}{ Mean \pm s.d. } & \multicolumn{1}{c|}{ Range } & \multicolumn{1}{c|}{ Species } & \multicolumn{1}{c|}{ Mean \pm s.d. } & \multicolumn{1}{c|}{ Range } \\
\hline Ethene & $14.85 \pm 10.82$ & $0.68-47.41$ & Toluene & $1.61 \pm 0.94$ & $0.20-4.19$ \\
\hline Ethane & $14.47 \pm 8.10$ & $1.72-36.06$ & i-Pentane & $1.45 \pm 0.94$ & $0.17-4.49$ \\
\hline Acetylene & $9.69 \pm 6.06$ & $0.64-30.81$ & Dichloromethane & $1.39 \pm 0.70$ & $0.00-4.23$ \\
\hline Propane & $7.27 \pm 4.55$ & $0.88-21.27$ & Ethylacetate & $1.15 \pm 0.92$ & $0.01-3.92$ \\
\hline $1,3-$-Butadiene & $3.93 \pm 3.03$ & $0.11-12.38$ & Methylethylketone & $1.08 \pm 0.74$ & $0.15-3.57$ \\
\hline Propene & $3.67 \pm 2.97$ & $0.22-14.01$ & Chloromethane & $0.90 \pm 0.81$ & $0.01-6.46$ \\
\hline n-Butane & $2.70 \pm 1.85$ & $0.35-9.09$ & n-Pentane & $0.85 \pm 0.57$ & $0.08-2.59$ \\
\hline i-Butane & $2.08 \pm 1.46$ & $0.21-7.21$ & n-Butylacetate & $0.63 \pm 0.44$ & $0.01-1.73$ \\
\hline Acetone & $2.02 \pm 0.92$ & $0.12-5.09$ & 1 -Butene & $0.60 \pm 0.40$ & $0.05-1.68$ \\
\hline Benzene & $1.62 \pm 1.14$ & $0.14-4.99$ & n-Hexane & $0.58 \pm 0.45$ & $0.05-2.36$ \\
\hline
\end{tabular}


the largest contribution to ambient VOCs in this heavy pollution episode, among which ethene and ethane were the most abundant VOC species. Benzene and toluene, which have been proved to be strong carcinogens $[1,3]$, were also important contributors to ambient VOCs.

\subsubsection{Comparison with previous studies}

Due to different emission sources and meteorological conditions in different regions, level and composition of ambient VOCs varied significantly. Table 3 summarizes top $10 \mathrm{VOC}$ species with the highest level observed in urban sites in previous studies. In general, levels of VOC species in this study were higher than those in other studies in China and comparative with those observed in Rome. The most abundant species measured in this study included ethane, ethene, propane and acetylene, while aromatics were present at relatively lower levels. In studies conducted in Guangzhou, Shanghai and Rome, average mixing ratios of toluene and benzene were evidently higher than in this study, attributed to higher industrial and vehicular emissions. Level of propane in Guangzhou was pronouncedly higher than in other cities, caused by widespread use of liquid petroleum gas (LPG) vehicles in Guangzhou [15]. Due to inadequacy of public transport system in Rome, two-stroke mopeds were an important mode of transportation. This is the reason for high level of i-pentane in Rome [4].

Table 3: Top 10 most abundant species (ppbv) measured in urban sites in previous studies.

\begin{tabular}{|c|c|c|c|c|c|}
\hline Guangzhou $^{\mathrm{a}}$ & Mean \pm s.d. & Shanghai ${ }^{\text {b }}$ & Mean \pm s.d. & Rome $^{\mathrm{c}}$ & Mean \pm s.d. \\
\hline Propane & $10.7 \pm 8.9$ & Propane & $3.98 \pm 2.41$ & i-Pentane & $18.40 \pm 15.78$ \\
\hline Acetylene & $7.3 \pm 5.2$ & Toluene & $3.21 \pm 2.29$ & Toluene & $10.58 \pm 8.58$ \\
\hline Toluene & $7.0 \pm 7.3$ & Butane & $1.62 \pm 1.26$ & Ethene & $9.42 \pm 2.52$ \\
\hline Ethene & $6.8 \pm 5.1$ & Chloromethane & $1.62 \pm 2.89$ & n-Butane & $7.48 \pm 7.18$ \\
\hline Ethane & $5.6 \pm 3.3$ & Isopentane & $1.53 \pm 1.13$ & Propene & $6.97 \pm 4.75$ \\
\hline n-Butane & $5.2 \pm 4.4$ & 1,2-Dichloroethane & $1.51 \pm 1.80$ & $\mathrm{~m} / \mathrm{p}$-Xylene & $6.03 \pm 5.04$ \\
\hline Propene & $3.2 \pm 3.0$ & Benzene & $1.50 \pm 0.99$ & Benzene & $3.29 \pm 1.61$ \\
\hline i-Butane & $2.9 \pm 2.6$ & $\mathrm{~m} / \mathrm{p}$-Xylene & $1.32 \pm 1.05$ & i-Butane & $2.11 \pm 2.25$ \\
\hline i-Pentane & $2.7 \pm 2.3$ & Ethyl acetate & $1.32 \pm 1.49$ & 3-Methylpentane & $2.04 \pm 1.49$ \\
\hline Benzene & $2.4 \pm 1.9$ & i-Butane & $1.01 \pm 0.86$ & n-Pentane & $1.62 \pm 1.23$ \\
\hline
\end{tabular}

${ }^{\mathrm{a}}$ Liu et al. [19]; ${ }^{\mathrm{b}}$ Cai et al. [10]; ${ }^{\mathrm{c}}$ Fanizza et al. [4].

\subsubsection{Diurnal variations of ambient VOCs}

Diurnal patterns of ambient VOC groups and important VOC species are respectively plotted in Figure 2(a) and Figure 2(b). VOC groups including alkanes, alkenes and alkynes followed a similar pattern of average diurnal variation, so did the four most abundant VOC species: mixing ratios declined after sunrise and reached a minimum value at noon (12:00-14:00), then increased in the afternoon 
and reached a maximum value at night (22:00-23:00). This was possibly due to descending boundary layer at night and potential night emissions. Since acetylene emissions are usually associated with combustion of fossil fuels [16] and biomass burning [20], we speculated that coal combustion and biomass burning were significant night time sources of VOCs in the wintertime of Beijing. There was no obvious diurnal variation in OVOCs, evidenced by secondary formation during the daytime, photolysis loss, and variation in the boundary layer $[13,21]$.

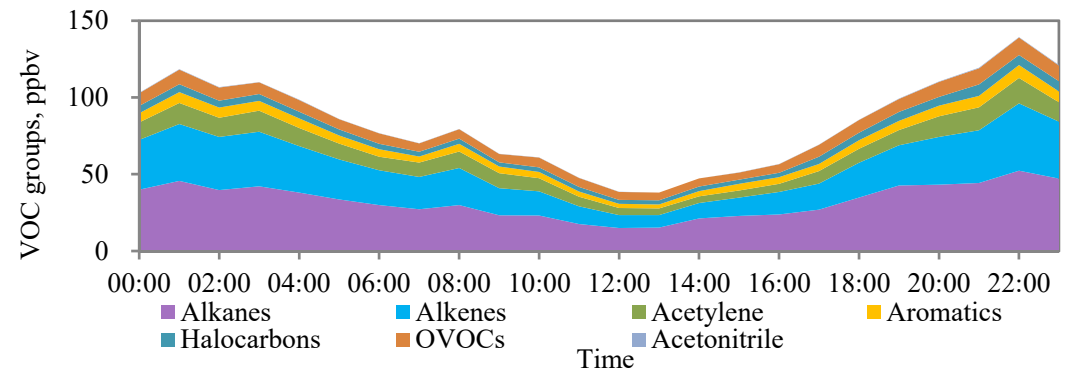

(a)

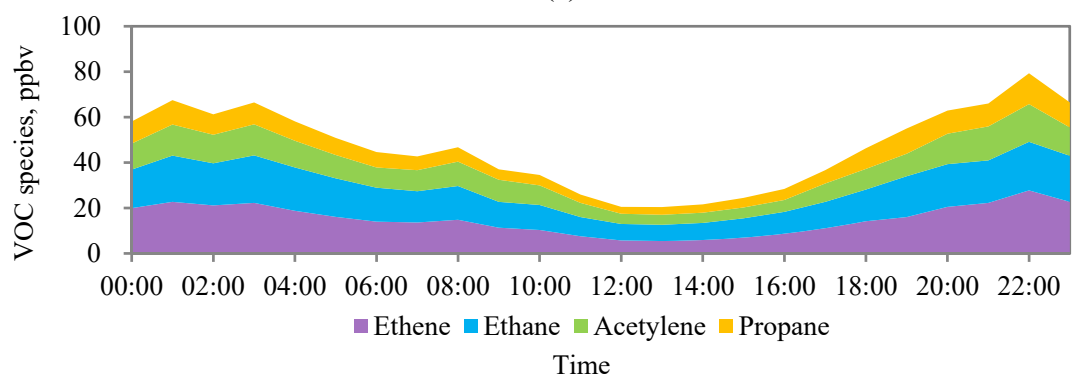

(b)

Figure 2: Diurnal variations in mixing ratios (a) VOC groups (b) The four most abundant VOC species.

\subsection{Interspecies correlations and major VOC sources}

Interspecies correlation between benzene-acetylene can direct at stationary (industrial and residential sources), traffic-related and transport sources, since emissions of acetylene and benzene in China are quite similar [16], both associated with incomplete combustion of various types of fossil fuels [16] and biomass burning [20]. As is shown in Figure 3(a), mixing ratios of benzene and acetylene during the whole measurement period correlated well, with a slope of 0.17 and Pearson correlation coefficient (R) of 0.917. Compared with the slope of 0.29 for stationary sources, 0.11 for transport sources [17], and 0.13 for traffic-related sources [18], the slope obtained for benzene-acetylene in this study reveals that traffic-related sources were likely one of the sources of ambient VOCs during the investigation period. To find out whether stationary sources played a role, the interspecies correlation between toluene and acetylene were also studied. 
Toluene most likely comes from activities including stationary sources [16]. The correlation plot between toluene and acetylene, as is shown in Figure 3(b), reveals strong correlation $(\mathrm{R}=0.925)$. The slope is 0.14 , close to the slope for stationary combustion (0.12, Klimont et al. [17]) and much lower than the slope for transport sources (0.24, Barletta et al. [18]; 0.37, Klimont et al. [17]). The result shows that both traffic-related sources and stationary sources contributed to ambient VOCs in this heavy pollution episode.

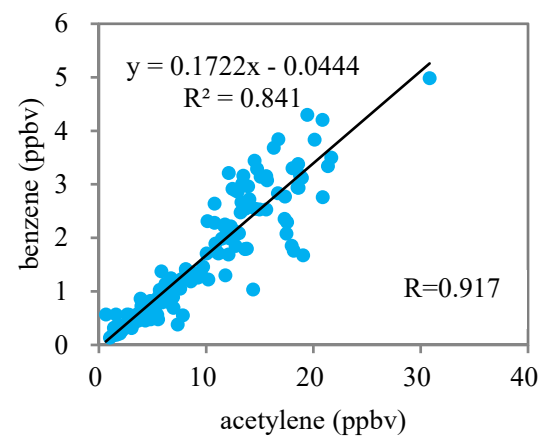

(a)

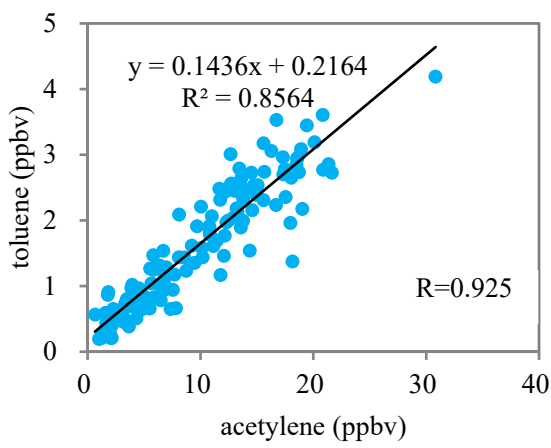

(b)

Figure 3: Correlation plots between (a) benzene and acetylene (b) toluene and acetylene, during the investigation period. The plots are shown for linear best square fit. Pearson correlation coefficients (R), slopes and $\mathrm{R}^{2}$ values are labeled.

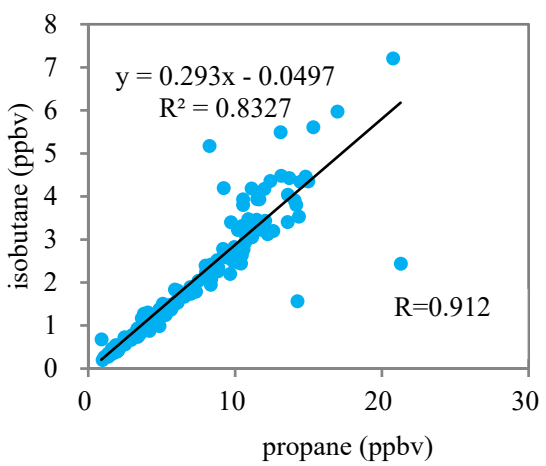

(a)

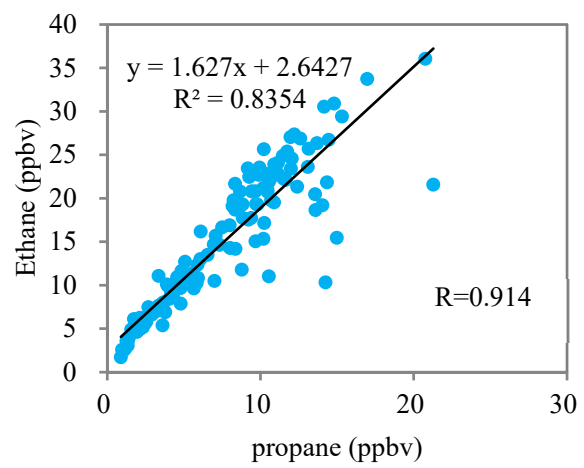

(b)

Figure 4: Correlation plots between (a) propane and isobutene (b) propane and ethane, during the investigation period. The plots are shown for linear best square fit. Pearson correlation coefficients (R), slopes and $\mathrm{R}^{2}$ values are labeled. 
To further investigate and specify the major sources of ambient VOCs in the observation period, the correlations between isobutane and propane, propane and ethane were analyzed. Propane is one of the major components of LPG fuels [19]. For LPG leakage, major emissions include light alkanes (i.e. propane, isobutene, n-butane) and some alkenes. As is shown in Figure 4(a), isobutane and propane show strong correlations $(\mathrm{R}=0.912)$, with a slope of 0.29 , very close to the slope of 0.28 derived in Liu et al. [19] indicating that LPG-powered vehicles and LPG leakage contributed considerably to ambient VOCs during the observation period. Figure 4(b) displays the correlation between ethane and propane, directing at the significance of fossil fuel combustion and biomass burning. These two species correlated well $(\mathrm{R}=0.914)$, with a slope of 1.63 , comparable to the slope indicating fossil fuel combustion and biomass burning (1.9, Suthawaree et al. [16]). To sum up, LPG-related sources (LPG-vehicles, LPG leakage, etc.) as well as combustion (fossil fuel, biomass) were the major VOC sources during the heavy pollution episode.

\section{Conclusion}

Ambient VOCs measurement was performed at an urban site in Beijing during a heavy pollution episode in December, 2014. In the whole investigation period, mixing ratios of total VOCs increased with fluctuation to a peak value of more than $250 \mathrm{ppbv}$, and then decreased drastically due to the passage of clean air mass. After that, two extinct peaks can be seen in the time series. Alkanes, with an average mixing ratio of 32.08 ppbv, were largest contributor, accounting for $38.9 \%$ of total VOCs, followed by alkenes (23.65 ppbv, $28.7 \%$ ), acetylene $(9.69$ ppbv, 11.8\%), OVOCs (7.41 ppbv, 9.0\%), aromatics (5.22 ppbv, 6.3\%), and halocarbons (4.15 ppbv, 5.0\%). The most abundant VOC species included ethene, ethane, acetylene and propane, with an average mixing ratio of 14.85, 14.47, 9.69 and $7.27 \mathrm{ppbv}$, respectively. The chemical compositions and concentration levels of ambient VOCs in this study were compared with those obtained in previous studies. Diurnal variation patterns of alkanes, alkenes and alkynes, as well as the four most abundant species were similar. Due to descending boundary layer at night and possible night emissions, peak values of VOC mixing ratios were observed at night. There were no extinct diurnal variation in OVOCs, due to secondary formation during daytime, photolysis loss, and variation in the boundary layer. The strong correlations between selected VOC species which served as source indicators and the linear regression slopes which were comparable with previous studies revealed that the major VOC sources during the heavy pollution episode in December 2014 in Beijing included LPG-related sources (LPG-powered vehicles, LPG leakage, etc.) and combustion sources (fossil fuel combustion, biomass burning, etc.).

Results of this study indicate that vehicular emission and combustion are closely related to heavy pollution during wintertime in Beijing. Our findings can also function in the policy making on VOC emission control measures. Details on ambient VOCs in this study can provide basic information for further studies on the formation of SOA and relevant health effects. It is advised that source 
apportionment approaches be used in future studies to recognize the emission sources of ambient VOCs on a more quantitative basis.

\section{Acknowledgement}

This study was funded by the Natural Science Foundation key project (grant no. 91544106).

\section{References}

[1] Liu J.F., Mu Y.J., et al., Atmospheric levels of BTEX compounds during the 2008 Olympic Games in the urban area of Beijing. Science of the Total Environment, 408, pp. 109-116, 2009.

[2] Derwent R. G., Jenkin M. E., et al, Secondary organic aerosol formation from a large number of reactive man-made organic compounds. Science of The Total Environment, 408(16), pp. 3374-3381, 2010.

[3] Mehlman M.A., Dangerous properties of petroleum-refining products: carcinogenicity of motor fuels (gasoline). Teratogenesis, carcinogenesis, and mutagenesis, 10, pp. 399-408, 1990.

[4] Fanizza C., Incoronato F., et al., Volatile organic compound levels at one site in Rome urban air. Atmospheric Pollution Research, 5(2), pp. 303-314, 2014.

[5] Tao J., Gao J., et al., $\mathrm{PM}_{2.5}$ pollution in a megacity of southwest China: source apportionment and implication. Atmospheric Chemistry and Physics, 14(16), pp. 8679-8699, 2014.

[6] Tang G., Li X., Wang Y., Xin J. and Ren X., Surface ozone trend details and interpretations in Beijing, 2001-2006. Atmospheric Chemistry and Physics, 9, pp. 8813-8823, 2009.

[7] Guo S., Hu M., et al., Elucidating severe urban haze formation in China. Proceedings of the National Academy of Sciences, 111(49), pp. 17373$17378,2014$.

[8] Wang H. L., Qiao L.P., et al., PM2.5 pollution episode and its contributors from 2011 to 2013 in urban Shanghai, China. Atmospheric Environment, 123, pp. 298-305, 2015.

[9] http://www. tianqihoubao.com/aqi/beijing-201412.html

[10] Cai C.J., Geng F.H., et al., Characteristics of ambient volatile organic compounds (VOCs) measured in Shanghai, China. Sensors, 10, pp. 78437862, 2010.

[11] Wang T., Wong C.H., et al., Relationships of trace gases and aerosols and the emission characteristics at Lin'an, a rural site in eastern China, during spring 2001. Journal of Geophysical Research, 109(D19), 2004.

[12] Parra M. A., González L., et al., Spatial and temporal trends of volatile organic compounds (VOC) in a rural area of northern Spain. Science of the Total Environment, 370(1), pp. 157-167, 2006. 
[13] Li J., Xie S. D., et al., Characterization of ambient volatile organic compounds and their sources in Beijing, before, during, and after AsiaPacific Economic Cooperation China 2014. Atmospheric Chemistry and Physics, 15(14), pp. 7945-7959, 2015.

[14] Yuan B., Chen W.T., et al., Measurements of ambient hydrocarbons and carbonyls in the Pearl River Delta (PRD), China. Atmospheric Research, 116, pp. 93-104, 2012.

[15] Li L.Y., Xie S.D., et al., Characteristics of volatile organic compounds and their role in ground-level ozone formation in the Beijing-Tianjin-Hebei region, China. Atmospheric Environment, 113, pp. 247-254, 2015.

[16] Suthawaree J., Kato S., et al., Measurements of volatile organic compounds in the middle of Central East China during Mount Tai Experiment 2006 (MTX2006): observation of regional background and impact of biomass burning. Atmospheric Chemistry and Physics, 10, pp. 1269-1285, 2010.

[17] Klimont Z., Streets D.G., et al., Anthropogenic emissions of non-methane volatile organic compounds in China. Atmospheric Environment, 2002, 36, pp. 1309-1322, 2002.

[18] Barletta B., Meinardi S., et al., Volatile organic compounds in 43 Chinese cities. Atmospheric Environment, 39(32), pp. 5979-5990, 2005.

[19] Liu Y., Shao M., et al., Volatile organic compound (VOC) measurements in the Pearl River Delta (PRD) region, China. Atmospheric Chemistry and Physics, 8, pp. 1531-1545, 2008.

[20] de Gouw, J. A., et al., Chemical composition of air masses transported from Asia to the U.S. West Coast during ITCT 2K2: Fossil fuel combustion versus biomass-burning signatures. Journal of Geophysical Research: Atmospheres, 109(D23), doi:10.1029/2003JD004202, 2004.

[21] Chen W. T., Shao M., et al., Understanding primary and secondary sources of ambient carbonyl compounds in Beijing using the PMF model. Atmospheric Chemistry and Physics, 14(6), pp. 3047-3062, 2014. 